\title{
Inhibitory Effect of Mitomycin C on Proliferation of Primary Cultured Fibroblasts from Human Airway Granulation Tissues
}

\author{
Nan Chen Jie Zhang Min Xu Yu Ling Wang Ying Hua Pei \\ Department of Pulmonary Medicine, Beijing Tian Tan Hospital, Capital Medical University, Beijing, China
}

\author{
Key Words \\ Fibroblasts · Granulation tissue - Benign tracheal stenosis · \\ Mitomycin C
}

\begin{abstract}
Background: Airway granulation tissue and scar formation pose a challenge because of the high incidence of recurrence after treatment. As an emerging treatment modality, topical application of mitomycin $C$ has potential value in delaying the recurrence of airway obstruction. Several animal and clinical studies have already proven its feasibility and efficacy. However, the ideal dosage has still not been determined. Objectives: To establish a novel method for culturing primary fibroblasts isolated from human airway granulation tissue, and to investigate the dose-effect of mitomycin $C$ on the fibroblast proliferation in vitro, so as to provide an experimental reference for clinical practitioners. Methods: Granulation tissues were collected during the routine bronchoscopy at our department. The primary fibroblasts were obtained by culturing the explanted tissues. The cells were treated with different concentrations of mitomycin $C(0.1,0.2,0.4,0.8$ and $1.6 \mathrm{mg} / \mathrm{ml})$ for $5 \mathrm{~min}$ followed by additional 48-hour culture before an MTT assay was performed to measure cell viability. Results: MTT assay showed that mitomycin $C$ reduced cell viability at all tested concentrations. The inhibitory ratios were 10.26, 26.77, $32.88,64.91$ and $80.45 \%$ for cells treated with mitomycin C at $0.1,0.2,0.4,0.8$ and $1.6 \mathrm{mg} / \mathrm{ml}$, respectively. Conclusions:
\end{abstract}

Explant culture is a reliable method for culturing primary fibroblasts from human airway granulation tissue, and mitomycin $C$ can inhibit proliferation of the fibroblasts in vitro.

Copyright $\odot 2013$ S. Karger AG, Basel

\section{Introduction}

Management of benign tracheal stenosis (BTS) remains a challenging problem for the pulmonologists. The underlying mechanism of BTS is an aberrant mucosal wound-healing response that leads to excessive fibroplasia [1]. Although a variety of interventional bronchoscopic techniques have recently been developed to provide immediate relief from airway obstruction, they may cause secondary damage to the airway structures, resulting in excessive granulation tissue and scar formation during the wound-healing procedure, and ultimately restenosis.

The pathological characteristics of BTS are similar to those of 'keloid' or 'hypertrophic scars'. Moreover, substantial evidence indicates that the development of a keloid or hypertrophic scar is associated with abnormal fibroblast activity in the wound bed $[2,3]$. Thus, inhibiting proliferation of fibroblasts and inducing fibroblast apoptosis with pharmaceutical reagents may be a promising approach to treat airway restenosis. Topical application of mitomycin $\mathrm{C}$ (MMC) is an emerging adjuvant therapy for BTS, and its efficacy has been evaluated in animal and clinical studies. In current studies, an amount of $0.4 \mathrm{mg} /$

\section{KARGER}

E-Mail karger@karger.com

www.karger.com/res
(C) 2013 S. Karger AG, Basel

0025-7931/13/0856-0500\$38.00/0
Dr. Jie Zhang

Department of Pulmonary Medicine

Beijing Tian Tan Hospital, Capital Medical University

Beijing 100050 (China)

E-Mail zhangjie6218@163.com 
$\mathrm{ml} \mathrm{MMC} \mathrm{is} \mathrm{topically} \mathrm{applied} \mathrm{directly} \mathrm{to} \mathrm{the} \mathrm{tracheal} \mathrm{mu-}$ cosa for 2-5min [4]; however, the efficacy and effective concentration of MMC in clinics is still under debate.

In this study, we developed a novel method for culturing primary fibroblasts that have been isolated from human airway granulation tissues. In addition, we investigated the effect of different concentrations of mitomycin $\mathrm{C}$ on the fibroblast proliferation in vitro, so as to provide an experimental reference for clinical practice.

\section{Material and Methods}

\section{Reagents}

Dulbecco's modified Eagle's medium (DMEM) high glucose medium, fetal bovine serum (FBS) and penicillin/streptomycin were purchased from HyClone, USA. Trypsin-EDTA (0.25\%) was obtained from Gibco, USA. Dimethylsulfoxide (DMSO) and 3-[4, 5-demethylthiazol-2, 5-diphenyl-2H-tetrazolium bromide] (MTT) were purchased from Amresco, USA. MMC was obtained from Kyowa Hakko Kogyo, Japan, and moxifloxacin hydrochloride and sodium chloride injection were from Avelox, Bayer, Germany.

\section{Human Airway Granulation Tissue}

Six samples of granulation tissue ( 2 male and 4 female) were collected during routine bronchoscopy at our department from April to June, 2011. The causes of BTS were endobronchial tuberculosis $(n=3)$ and prolonged intubation $(n=3)$. The study protocol was approved by the IRB of Beijing Tiantan Hospital affiliated to Capital Medical University (approval No. kylw-2010-001), and each participant signed an informed consent document.

\section{Culturing Fibroblasts from Human Airway Granulation}

Tissue

During bronchoscopy, small pieces of granulation tissue were obtained with fine forceps. In order to preserve the viability of the cells, electrocautery and other thermal damage technique were avoided while obtaining the tissue. Tissue was washed in sterilized saline once and in Avelox twice. It was then kept in culture medium (DMEM supplemented with $10 \%$ FBS and $1 \%$ penicillin/streptomycin) and transferred to the laboratory at $4^{\circ} \mathrm{C}$ as soon as possible. The upper airway is a nonsterile environment, so the principles of asepsis must be strictly obeyed in order to prevent additional contamination.

In the laminar flow hoods, all samples were repeatedly washed in sterilized saline to remove blood and attached impurities. They were then rinsed twice in 50\% Avelox (diluted with saline) and in sterilized saline once. As most of the patients with prolonged intubation or tracheostomy usually suffer from severe airway infection, penicillin/streptomycin was not sufficient for killing the bacteria. So we chose Avelox, the antibacterial spectrum of which was broader and achieved better results. We employed an explant culture approach to culture the fibroblasts as it could retained all of the secreted growth factors for cell proliferation. Tissue was cut into small pieces (approx. $1-2 \mathrm{~mm}^{3}$ ) before being transferred into a standard $1 \%$-gelatin-coated $25-\mathrm{mm}^{2}$ culture flask. The flask was turned upside down, and was supplied with $1 \mathrm{ml}$ of culture medi- um (DMEM supplemented with 20\% FBS and 1\% penicillin/streptomycin) and then placed in a $37^{\circ} \mathrm{C}, 5 \% \mathrm{CO}_{2}$-containing incubator. After $4 \mathrm{~h}$, the tissue pieces had already adhered to the bottom, and the flask was turned over carefully and the medium changed daily. There should be no more than $1 \mathrm{ml}$ of culture medium in the flask, otherwise the tissue pieces might be washed away. When the cells were confluent, the tissue pieces were taken out, and cells were transferred to $25-\mathrm{cm}^{2}$ culture flasks using trypsin/EDTA.

\section{Mitomycin C Treatment of Fibroblasts}

Fibroblasts at passage 4 were treated with $0.125 \%$ trypsin to prepare a single cell suspension. Five thousand cells in $180 \mu \mathrm{l} \mathrm{me-}$ dium were seeded into 96-well plates for 24-hour incubation. There were 3 groups of wells: the experimental group consisted of cells which would be treated with different concentrations of MMC, the control group consisted of cells treated with PBS as a vehicle control and the blank wells containing culture medium but no cells. After 24 hours of incubation, fibroblasts in the experimental group were treated with MMC at concentrations of $0.1,0.2,0.4$, 0.8 and $1.6 \mathrm{mg} / \mathrm{ml}$ respectively. After $5 \mathrm{~min}$, the fibroblasts were then washed immediately 3 times with $200 \mu$ PBS and incubated in culture medium for an additional $48 \mathrm{~h}$. Four hours before the end of the incubation, $20 \mu \mathrm{l}$ of $5 \mathrm{mg} / \mathrm{ml}$ MTT was added to each well. Incubation took place for $4 \mathrm{~h}$ in the absence of light. Then the medium in each well was removed and the precipitates were resuspended in $150 \mu \mathrm{l}$ DMSO. The optical density (OD) of each well was measured using an ELISA plate reader at a wavelength of $570 \mathrm{~nm}$. The inhibitory rate was calculated by the following equation:

$\%$ inhibition $=1-(\mathrm{OD}$ value in the experimental group $-\mathrm{OD}$ value in the blank well)/(OD value in the control group - OD value in the blank well) $\times 100 \%$.

\section{Statistical Analysis}

All results are expressed as mean \pm standard error of the mean. ANOVA was used to compare cell viability. Statistical analysis was performed using SPSS 16.0 software (SPSS Inc.) and $\mathrm{p}<0.05$ was considered statistically significant.

\section{Results}

\section{Culture of Fibroblasts from Human Airway \\ Granulation Tissue}

The adherent tissue pieces had poor light transmission, and appeared dark brown under an inverted microscope. Fibroblast-like cells were observed to migrate from the tissue pieces 3 days after explantation (fig. 1a). The morphology of the cells was a typical elongated spindle shape with a large cell body and a strong refraction index. After 9-11 days of culture, cells reached $90 \%$ confluence and were passaged with $0.125 \%$ trypsin-EDTA (fig. $1 \mathrm{~b}$, c).The cells adhered to the flask rapidly and extended gradually. The morphology of the cell was still a typical elongated spindle shape and the cells were healthy (fig. 1d). Cells were subcultured again when they formed a monolayer. 

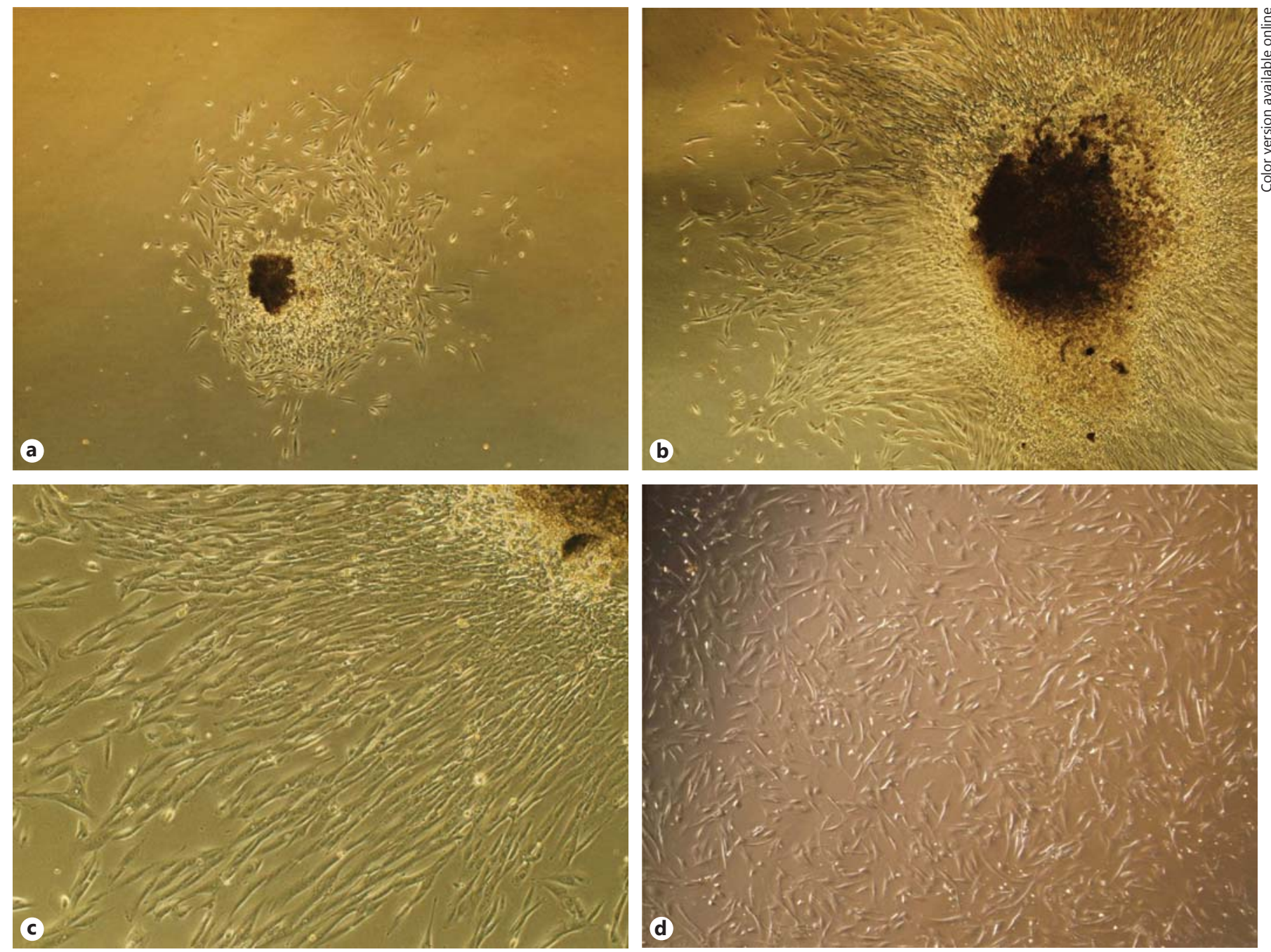

Fig. 1. Morphology of fibroblasts isolated from human airway granulation tissue. a Three days after explantation, fibroblast-like cells were observed to migrate from the tissue piece. The cells were a typical elongated spindle shape with a large cell body and a strong refraction index. $\times 40 . \mathbf{b}$, c Eleven days after explantation, a large

Table 1. Inhibitory effects of MMC on fibroblast proliferation

\begin{tabular}{lll}
\hline Group mg/ml & OD value & Inhibitory ratio (\%) \\
\hline Control & $0.955 \pm 0.053$ & 0 \\
$0.1 \mathrm{mg} / \mathrm{ml}$ & $0.857 \pm 0.037$ & 10.26 \\
$0.2 \mathrm{mg} / \mathrm{ml}$ & $0.699 \pm 0.034^{\mathrm{a}, \mathrm{b}}$ & 26.77 \\
$0.4 \mathrm{mg} / \mathrm{ml}$ & $0.641 \pm 0.030^{\mathrm{a}}$ & 32.88 \\
$0.8 \mathrm{mg} / \mathrm{ml}$ & $0.335 \pm 0.013^{\mathrm{a}, \mathrm{b}}$ & 64.91 \\
$1.6 \mathrm{mg} / \mathrm{ml}$ & $0.187 \pm 0.016^{\mathrm{a}, \mathrm{b}}$ & 80.45 \\
\hline
\end{tabular}

\footnotetext{
${ }^{\mathrm{a}} \mathrm{p}<0.01$ compared to control.

${ }^{\mathrm{b}} \mathrm{p}<0.01$ compared to former group.
}

number of cells migrated from the tissue piece and formed a monolayer. The cells were typically elongated and spindle-shaped. $\times 40, \times 100$. d The passaged cells adhered to the flask rapidly and extended gradually. The morphology of the cell was still a typical elongated spindle shape and the cells were healthy.

Dose-Dependent Effects of Mitomycin C on Fibroblast Viability

The fibroblast cell viability decreased after a short exposure to MMC of $5 \mathrm{~min}$. The MTT assay was performed for the fibroblasts $48 \mathrm{~h}$ after MMC treatment at concentrations of $0.1,0.2,0.4,0.8$ and $1.6 \mathrm{mg} / \mathrm{ml}$, and the $\mathrm{MMC}$ inhibitory ratios were $10.26,26.77,32.88,64.91$ and $80.45 \%$ respectively (table 1 ).

Compared to the control, OD value decreased in all cells of the MMC-treated group. However, only a minimal inhibition was observed in the wells treated with low MMC concentration, i.e. $0.1 \mathrm{mg} / \mathrm{ml}(\mathrm{p}>0.05)$. In com- 
parison to the control, strong inhibitory effects were achieved in the fibroblasts treated with MMC at concentrations of $0.2-1.6 \mathrm{mg} / \mathrm{ml}(\mathrm{p}<0.01)$. In particular, significant inhibitory effects were seen when the concentrations increased from 0.4 to $0.8 \mathrm{mg} / \mathrm{ml}$ or from 0.8 to 1.6 $\mathrm{mg} / \mathrm{ml}(\mathrm{p}<0.01)$.

\section{Discussion}

The treatment modality of BTS mainly includes surgical resection and endoluminal management. There is no doubt that resection and reconstruction surgery are the better choice for a more satisfying long-term benefit. However, not all of the patients were candidates for this procedure due to their poor condition. Scarring and recurrent stricture at the surgical sites remain important issues in $4-14 \%$ of patients who undergo a lengthy resection or when there is tension at the sites of anastomosis or anastomotic infection [5-7]. Under these circumstances, endoluminal treatment is the only solution to maintain airway patency. However, although endoluminal approaches can provide immediate relief from airway obstruction and result in an improvement in luminal patency, they cannot provide long-term benefits. A high rate of restenosis ranging from 40 to $70 \%$ has been reported after endoscopic treatment [8], which calls for more advanced therapies in order to achieve better results.

Topical application of MMC is a promising adjuvant therapeutic modality for BTS. Fibroblasts are the key component of granulation tissue, and they play a critical role in the development of granulation and scar formation. Abnormal fibroblasts are resistant to apoptosis signals and are an originator of excessive extracellular matrices $[1,3]$. MMC displays antimetabolite and antiproliferative properties by inhibiting cell DNA synthesis or suppressing RNA and protein synthesis [4, 9], and has been shown to be a strong inhibitor of fibroblast proliferation in wound-healing processes when applied topically [10]. Some evidence suggests that this inhibition is caused by apoptosis [11-13]. The history of using MMC to prevent postoperative scar formation dates back to 1963 , when it was first used in pterygium surgery and reduced the recurrence rate from 80 to $3 \%[4,14]$. This led to other uses of topical MMC in ophthalmic and otolaryngological surgery, such as glaucoma filtration, dacrocystorhinostomy, myringotomy and the treatment of synechia and stenosis after endoscopic sinus surgery. $[4,15]$.

Nowadays, MMC has been used successfully as an adjuvant therapy in a variety of airway procedures. Among them, the most common indication is the treatment of laryngotracheal stenosis due to postintubation stenosis, idiopathic subglottic stenosis or Wegener's granulomatosis $[8,16-18]$. Furthermore, the efficacy of topical MMC in the treatment of sarcoidosis-related bronchial stenosis, obstructive airway granulomas and anastomotic stricture after tracheal reconstruction has also been reported [19-21].

However, although the feasibility and efficacy of topical MMC have already been extensively proven by previous studies, many questions and technical difficulties remain. No literature to date reports on the optimal dose of topical MMC. Although our study has illustrated the dose-effect of MMC on fibroblast proliferation in vitro, these results are not sufficient to determine clinically meaningful dosages. Cytological experiments could not completely simulate complex in vivo environments. The performance of MMC is affected by drug absorption, cell interactions and other factors when applied in clinical practice. The optimal dosage should also not be determined solely on the basis of the inhibitory ratio of fibroblast proliferation. It is well known that wound healing is a dynamic and complex process regulated by a wide range of coordinated cellular and humoral reactions. In addition to fibroblasts, the structural and functional integrity of epithelial and other cellular components is also necessary for the wound-healing process. It has been found that once an open wound is covered with a complete epithelium, the inflammatory response resolves rapidly. Apoptosis signals have also been found to originate from the epithelium [3]. Thus, in determining the optimal dosage, we should take into account the influence of MMC on other cellular components.

In addition, MMC should be applied specifically to the stenosed mucosa in order to prevent MMC-related injury to the adjacent mucosa. However, although researchers have made a number of attempts, it is still difficult for clinical practitioners to deliver MMC directly into the target tissue during the endoscopic treatment. In most of the studies, the MMC solution was applied to the stenosed segment via the working channel of the broncoscope using a forceps to hold a pledget soaked with MMC solution [22]. This may takes several minutes, and the central airway may be occluded during the procedure, limiting tolerability in the patient; thus, a rigid bronchoscopy together with general anesthesia is required. Some researchers achieved drug delivery by using a biopsy needle to inject drug solutions into the airway mucosa. This method can be dangerous for the patient because it is difficult to control the depth of the needle and it is easy to damage the flexible bronchoscope if the operator is not well trained [23]. One 
animal study assessed the feasibility and safety of administering MMC by inhalation. Although significant inhibition of scar formation was achieved and no local or systemic toxic effects were documented in that study, more such studies are needed to evaluate the optimal dose, exposure duration and safety profiles prior to application in humans [24]. Another method for applying MMC endoscopically is to use a microporous polytetrafluoroethylene catheter balloon to deliver the drug solution to the target tissue. The special balloon allows the fluid to leak across its porous surface once inflated beyond its threshold volume. This kind of microporous PTFE balloon catheter was originally designed to be used in vessels with thrombosis. It has also been used to deliver MMC into a stenosed pediatric esophagus. This is probably the most effective and precise method for the local delivery of MMC [25]. However, this equipment is not available in many countries and its use in the airway is limited because the largest diameter of the microporous PTFE balloon is $8 \mathrm{~mm}$.
In conclusion, our study describes the dose-effect relationship of MMC on inhibiting fibroblasts proliferation in vitro. However, further investigations are needed to illustrate the potential mechanism and an in vivo study is certainly required to further explore the ideal dosage and to observe the safety profiles in detail.

\section{Acknowledgments}

We acknowledge Zhi Gang Ouyang, $\mathrm{PhD}$ for his technical support and the colleagues of our hospital laboratory for their equipment support.

\section{Financial Disclosure and Conflicts of Interest}

This study was supported by a grant from Beijing Natural Science Foundation (No. 7102053).

\section{References}

1 Singh T, Sandulache VC, Otteson TD, et al: Subglottic stenosis examined as a fibrotic response to airway injury characterized by altered mucosal fibroblast activity. Arch Otolaryngol Head Neck Surg 2010;136:163-170.

2 Dohar JE, Klein EC, Betsch JL, et al: Acquired subglottic stenosis - depth and not extent of the insult is key. Int J Pediatr Otorhinolaryngol 1998;46:159-170.

-3 Greenhalgh DG: The role of apoptosis in wound healing. Int J Biochem Cell Biol 1998; 30:1019-1030.

-4 Hirshoren N, Eliashar R: Wound-healing modulation in upper airway stenosis-myths and facts. Head Neck 2009;31:111-126.

$\checkmark 5$ Melkane AE, Matar NE, Haddad AC, et al: Management of postintubation tracheal stenosis: appropriate indications make outcome differences. Respiration 2010;79:395-401.

6 Fernando HC, Sherwood JT, Krimsky W: Endoscopic therapies and stents for benign airway disorders: where are we, and where are we heading. Ann Thorac Surg 2010;89:183-187.

7 Abbasidezfouli A, Akbarian E, Shadmehr $\mathrm{MB}$, et al: The etiological factors of recurrence after tracheal resection and reconstruction in post-intubation stenosis. Interact Cardiovasc Thorac Surg 2009;9:446-449.

8 Smith ME, Elstad M: Mitomycin C and the endoscopic treatment of laryngotracheal stenosis: are two applications better than one? Laryngoscope 2009;119:272-283.

-9 Hata T, Hoshi T, Kanamori K, et al: Mitomycin, a new antibiotic from Streptomyces. J Antibiot (Tokyo) 1956;9:141-146.
10 Yamamoto T, Varani J, Soong HK, et al: Effects of 5-fluorouracil and mitomycin $\mathrm{C}$ on cultured rabbit subconjunctival fibroblasts. Ophthalmology 1990;97:1204-1210.

11 Crowston JG, Chang LH, Constable PH, et al: Apoptosis gene expression and death receptor signaling in mitomycin-C-treated human tenon capsule fibroblasts. Invest Ophthalmol Vis Sci 2002;43:692-699.

12 Seong GJ, Park C, Kim CY, et al: Mitomycin$\mathrm{C}$ induces the apoptosis of human Tenon's capsule fibroblast by activation of c-Jun $\mathrm{N}$ terminal kinase 1 and caspase- 3 protease. Invest Ophthalmol Vis Sci 2005;46:3345-3552.

13 Kim TI, Choi SI, Lee HK, et al: Mitomycin C induces apoptosis in cultured corneal fibroblasts derived from type II granular corneal dystrophy corneas. Mol Vis 2008; $14: 1222-$ 1228.

14 Kunitomo N, Mori S: Studies on the pterygium. Part IV. A treatment of the pterygium by mitomycin-C instillation. Acta Soc Ophthalmol 1963;67:610-617.

15 Ubell ML, Ettema SL, Toohill RJ, et al: Mitomycin-C application in airway stenosis surgery: analysis of safety and costs. Otolaryngol Head Neck Surg 2006;134:403-406.

16 Simpson CB, James JC: The efficacy of mitomycin- $\mathrm{C}$ in the treatment of laryngotracheal stenosis. Laryngoscope 2006;116:1923-1925.

17 Perepelitsyn I, Shapshay SM: Endoscopic treatment of laryngeal and tracheal stenosis - has mitomycin C improved the outcome? Otolaryngol Head Neck Surg 2004;131:1620.
18 Roediger FC, Orloff LA, Courey MS: Adult subglottic stenosis: management with laser incisions and mitomycin-C. Laryngoscope 2008;118:1542-1546.

19 Teo F, Anantham D, Feller-Kopman D, et al: Bronchoscopic management of sarcoidosisrelated bronchial stenosis with adjunctive topical mitomycin C. Ann Thorac Surg 2010; 89:2005-2007.

20 Penafiel A, Lee P, Hsu A, et al: Topical mitomycin-C for obstructing endobronchial granuloma. Ann Thorac Surg 2006;82:e22-e23.

21 Ward RF, April MM: Mitomycin-C in the treatment of tracheal cicatrix after tracheal reconstruction. Int J Pediatr Otorhinolaryngol 1998;44:221-226.

22 Hartnick CJ, Hartley BE, Lacy PD, et al: Topical mitomycin application after laryngotracheal reconstruction: a randomized, doubleblind, placebo-controlled trial. Arch Otolaryngol Head Neck Surg 2001;127:1260-1264.

23 Simpson CB, White S, McGuff HS: Antitransforming growth factor beta as a treatment for laryngotracheal stenosis in a canine model. Laryngoscope 2008;118:546-551.

24 Fattaha HA, Hamza A, Gaafara A, et al: Inhalation mitomycin-C in the management of laryngeal fibrosis: rationale, benefits, and pitfalls. Int Congr Series 2003;1240:831-837.

25 Heran MKS, Pham TH, Butterworth S, et al: Use of a microporous polytetrafluoroethylene catheter balloon to treat refractory esophageal stricture: a novel technique for delivery of mitomycin C. J Pediatr Surg 2011;46:776779 